\section{Missbräuche in der ärztlichen Praxis}

Letztes Jahr haben sich die Medien ausführlich mit einem 11jährigen Buben beschäftigt, der sich an seiner jüngeren Stiefschwester vergriffen haben soll. Das Schicksal des jungen Tatverdächtigen hat ebenso Aufmerksamheit gefunden wie die harte Gangart der amerikanischen Justiz. Klagen von erwachsenen Missbrauchsopfern in der Schweiz sind dadurch vorübergehend in den Hintergrund getreten. Das Ausserordentliche hat das schon zur Gewohnheit Gewordene verdrängt.

Nur: Während die Medien an Aktualitäten und News interessiert sind, bleiben die Menschen mit Missbrauchserfahrungen an ihre Vergangenheit gebunden. Auch wenn sie bewusst zu vergessen suchen, kann der emotionale Schmerz immer wieder neu geweckt werden. Viele sind durch ihre Erlebnisse so gezeichnet, dass sie an psychischen oder somatischen Störungen leiden.

Gerade weil Medizinerinnen und Mediziner besonders häufig und besonders nahe mit Opfern von sexuellem Missbrauch zu tun haben, besteht auch das Risiko, dass sich sexueller Missbrauch im medizinischen Setting wiederholen oder - seltener - erstmals ereignen kann. Wie die Statistiken lehren, folgen auf früheren Missbrauch nicht selten weitere Missbrauchserfahrungen. Abhängigkeitsverhältnisse vergrössern diese Wiederholungsgefahr. Davon sind auch Arzt-Patienten-Verhältnisse nicht ausgenommen. Deshalb tut eine Auseinandersetzung mit der Missbrauchsthematik im Ärztestand not.

Zuerst und vor allem ist Prävention angesagt sowie das Erlernen eines adäquaten Umganges mit Missbrauchsopfern. Aber auch Missbrauchsvorwürfe gegenüber Ärzten sind sorgfältig zu prüfen. Ist eine Grenzüberschreitung vorgefallen, so bedürfen Opfer und oft auch Täter Hilfe. Das Opfer hat zudem Anrecht auf ein gerechtes Vergleichsverfahren und wenn nötig - auf eine klärende Rechtsprechung. Öffentlichkeit ist bei Missbrauchsvorwürfen meist für alle Beteiligten nachteilig, aber noch schlimmer ist ein ungeahndeter Missbrauch unter dem Schutzmantel ärztlicher Verschwiegenheit.

In dieser Ausgabe der Schweizerischen Ärztezeitung nimmt Dr. Tschan das ebenso wichtige wie heikle Thema "Missbräuche in der ärztlichen Praxis" auf. Besonders verdienstvoll sind seine konkreten Vorschläge, die aus der Praxis stammen und Punkt für Punkt diskutiert werden können. Dr. Tschan hat während vieler Jahre in der Anlauf- und Beratungsstelle für Missbrauchsopfer und-täter in Basel-Stadt gearbeitet. Die Lektüre seiner zusammengefassten Erfahrungen und seiner Lösungsvorschläge lassen mich den Schluss ziehen, dass das Verdrängen und Verschweigen der Missbrauchsthematik in der ärztlichen Praxis ebenso gefährlich wäre wie der Versuch, diese heikle Angelegenheit ausschliesslich bürokratisch oder legalistisch zu lösen.

Prof. Dr. med. D. Hell, Psychiatrische Universitätsklinik, Zürich 